\title{
S3 Gallop
}

National Cancer Institute

\section{Source}

National Cancer Institute. S3 Gallop. NCI Thesaurus. Code C61455.

A finding which can be heard on auscultation of the heart in the setting of congestive heart failure. The sound of the S3 gallop, which immediately follows the second heart sound (S2) is thought to be produced by the sound of blood flowing into a noncompliant ventricle. 